\title{
Representative Model Compounds for Understanding the Pyrolytic Behavior of Pre-oxidized $\beta$-Ether-type Lignin
}

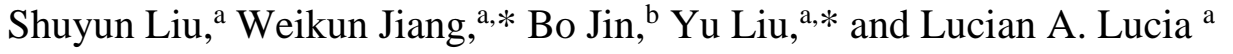

To achieve a better understanding of the pyrolysis behavior of pre-oxidized $\beta$-ether-type lignin, three $C_{a}=0$ type dimers with different substituent groups on the aromatic ring were synthesized and analyzed by a simultaneous thermal analysis instrument (STA), in-situ Fourier transform infrared spectroscopy (in-situ FTIR), and pyrolysis-gas chromatography/ mass spectrometry (Py-GC/MS). The results showed that major primary pyrolysis reactions of $\mathrm{C}_{\alpha}=\mathrm{O}$ type models normally occurred at 200 to 400 ${ }^{\circ} \mathrm{C}$, and connecting bridge structures of models were completely destroyed, causing the emission of abundant volatiles. Substituent groups of aromatic rings played direct roles in thermal stability of models, volatiles emission, product characteristics, and secondary reaction pathways of major primary products. Particularly, the aryl- $\mathrm{OCH}_{3}$ group clearly enhanced the reactivity of intramolecular linkages and was an important active functional group for secondary reactions. As major primary products and intermediates, guaiacol and 2-methoxy-benzaldehyde were formed via the cleavage of $\mathrm{C}_{\alpha}-\mathrm{O}$ and $\mathrm{C}_{\alpha}-\mathrm{C}_{\beta}$ bonds and could also be converted into phenol, benzaldehyde, and 2-methylphenol via rearrangement of aryl- $\mathrm{OCH}_{3}$ into an aryl- $\mathrm{CH}_{3}$ group or $-\mathrm{OCH}_{3}$ group removal. Oxidization of benzylic alcohol to benzylic ketone not only simplified depolymerization pathways, but also resulted in better selectivity of phenolic monomers and a predictable product distribution.
\end{abstract}

Keywords: Pre-oxidized lignin models; Pyrolysis behavior; Substituent groups; in-situ FTIR

Contact information: a: State Key Laboratory of Biobased Material and Green Papermaking College of Paper and Plant Resources Engineering, Qilu University of Technology, Jinan, Shandong 250353, PR China; $b$ : School of Chemistry and Chemical Engineering, Shandong University, Jinan, Shandong 250100, PR China; *Corresponding authors: weikun0709@126.com; leoliuyu@163.com

\section{INTRODUCTION}

Although oil refinery operations are the main source of chemicals in society today, a worldwide energy crisis and environmental concerns dictate consideration of alternative feedstock for chemicals such as renewables (Ralph et al. 2019). Lignocellulosic biomass is the only renewable organic carbon resource in nature, and it is mainly composed of hemicelluloses, cellulose, and lignin. For hemicellulose and cellulose, several mature utilization technologies have been adopted industrially for the production of biofuels and platform chemicals (Chen and Kuo 2011). Lignin, the most abundant and renewable source composed of aromatic units in nature, is quite valuable for producing value-added aromatic chemicals. Annually, millions of tons of alkali-soluble lignin and solid residue lignin are produced by the pulp and paper industry and bioethanol industry (No 2014; Farag and Chaouki 2015; Ong et al. 2019). Selective abstraction of desired aromatic and phenolic products from lignin should have constituted a renewable resource for these valuable 
chemicals. However, due to lignin's complexity and structural variety, all but a small percentage of the lignin is used in low-value commercial applications, such as fuel for heat and power applications (Han et al. 2018).

A representative lignin structure is illustrated in Fig. S1a (see Apptendix), and all these monomeric units contain a phenyl nuclei and a propyl side chain. Lignin is mainly composed of three primary precursors: sinapyl $(\mathrm{S})$, coniferyl $(\mathrm{G})$, and p-coumaryl $(\mathrm{H})$ alcohols; these are linked by ether linkages (e.g., $\beta-\mathrm{O}-4$ and $\alpha-\mathrm{O}-4)$ and carbon-carbon linkages (e.g., 5-5 and $\beta-1$ linkages) (Boerjan et al. 2003; Crestini et al. 2017). Theoretically, by breaking down these linkages, particularly the $\beta-\mathrm{O}-4$ bonds, which are the predominant linkage in lignin, a lot of high added value phenolic chemicals, such as benzene, phenol, guaiacol, vanillin, acetovanillone, and their derivates, could be obtained. Over the last few decades, a number of strategies (Li et al. 2015, Ong et al. 2019), such as pyrolysis, hydrogenolysis, hydrolysis, and enzymatic reactions, have been undertaken to depolymerize lignin. Among them, the most traditional lignin depolymerization strategy is pyrolysis, the rapid thermal decomposition at approximately $500{ }^{\circ} \mathrm{C}$ in the absence of oxygen and at atmospheric pressure to generate bio-oil, char, and gases (Kawamoto 2017).

Selective, high yield transformations of lignin into low molecular weight valueadded chemicals via direct pyrolysis has been studied in great detail for many years (Li et al. 2015), but little progress has been made toward industrialization. The most important cause of this may be a lack of systematic theory to guide lignin depolymerization arising from the complexity of the lignin macromolecule (Kawamoto 2017). To address these challenges, fast pyrolysis of lignin model compounds is used to simplify the pyrolysis processes; this approach provides an effective way to study the mechanism of lignin pyrolysis (Klein 1983; Britt et al. 2000; Chen et al. 2015; Watanabe et al. 2015; Kawamoto and Saka 2017). Especially, the $\beta$-aryl-ether linkages that are highlighted in blue color in Fig. S1a are ubiquitous and the most abundant lignin linkage, so the investigation of $\beta-\mathrm{O}-$ 4 bond cleavage has received the greatest attention. Klein (1983) proposed a six-centered retro-ene mechanism from kinetic analysis of the formation of styrene and phenol from phenethyl phenyl ether (PPE). Britt et al. (2000) studied the substituent effects of the $\mathrm{C}_{\beta}-$ phenyloxy groups on the cleavage reactivity and proposed several ionic and radical mechanisms for explaining pyrolytic cleavage of the $\beta$-ether bond. Watanabe et al. (2015) studied pyrolytic reactivities of deuterated $\beta$-ether-type lignin model dimers and found that hydrogen abstractions from $\mathrm{C}_{\alpha}$ and hydroxyl groups played direct roles in pyrolytic $\beta$-ether cleavage reactions. Kawamoto et al. $(2007,2008$, 2017) studied the role of substituent groups in char formation from lignin-related compounds. They observed the homolysis of the $\mathrm{O}-\mathrm{CH}_{3}$ bond to form methyl and pyrocatechol radicals and radical-induced rearrangement of aromatic $\mathrm{OCH}_{3}$ into aromatic $\mathrm{CH}_{3}$ structures were two important reactions, and put forward the existence of $\mathrm{C}_{\alpha}-\mathrm{OH}$ caused by the formation of condensed lignin or oligomer. The above previous studies together confirmed that substituent groups on the side-chain and aromatic ring have a significant effect on the pyrolytic behavior of lignin models and enrich the understanding of the lignin pyrolysis mechanism.

Following the progression of the experimental research of lignin pyrolysis mechanisms, it was found that highly reactive lignin side-chain (benzylic) carbocations (Fig. S1c) could attack electron-rich lignin aromatic rings, resulting in the secondary condensation of monomers (Wang et al. 2016). Based on this above theoretical research result, some scholars sought to finding how to inhibit the formation of benzylic carbocations. Hence, some promising modification methods of $\mathrm{C}_{\alpha}-\mathrm{OH}$ were first developed for facilitating the subsequent cleavage of lignin chemical bonds, such as the 
reduction of $\mathrm{C}_{\alpha}-\mathrm{OH}$ to $\mathrm{C}_{\alpha}-\mathrm{H}$, etherification of $\mathrm{C}_{\alpha}-\mathrm{OH}$ to $\mathrm{C}_{\alpha}-\mathrm{OCH}_{3}$ (Zhu et al. 2016), acetylation of $\mathrm{C}_{\alpha}, \gamma-\mathrm{OH}$ to $\mathrm{C}_{\alpha}, \gamma-\mathrm{OOCCH}_{3}$ (Lohr et al. 2015), and chemoselective oxidation of $\mathrm{C}_{\alpha} \mathrm{H}-\mathrm{OH}$ to $\mathrm{C}_{\alpha}=\mathrm{O}$ (Jiang et al. 2017; Zhang et al. 2017). Those methods were confirmed to increase the cleavage reactivity of the $\beta-\mathrm{O}-4$ bond via effectively decreasing the barrier of chemical bonds. Particularly, oxidation of the benzylic alcohol group (Fig. S1b) received more attention due to its low cost and technological simplicity (Jiang et al. 2017). However, there have been numerous reports on substituent groups in aromatic rings for the cleavage of $\beta-\mathrm{O}-4$ linkages in lignin model compounds, but relatively few reports of how those substituent groups affect pre-oxidized lignin model compounds that also contain a large number of oxygen functional groups, especially phenolic hydroxyl and methoxyl groups, which should also play a key role in $\beta-\mathrm{O}-4$ cleavage reactions and products distribution.

Hence, three dimers (Fig. 1) were synthesized to represent $\beta$-ether-type lignin fragments. These dimer models contained both the typical $\beta$-aryl-ether linkages and primary aromatic units and contained different oxygen functional groups. Pyrolysis characteristics of three $\beta$-ether-type polymers were investigated by a simultaneous thermal analysis instrument (STA), in-situ Fourier transform infrared spectroscopy (in-situ FTIR), and pyrolysis-gas chromatography/mass spectrometry (Py-GC/MS), and the specific product distributions and migration patterns of volatile functional groups with temperature were monitored in real time. The relationships between pyrolysis conditions and product characteristics were proposed explaining the pyrolytic reactivity of pre-oxidized lignin.

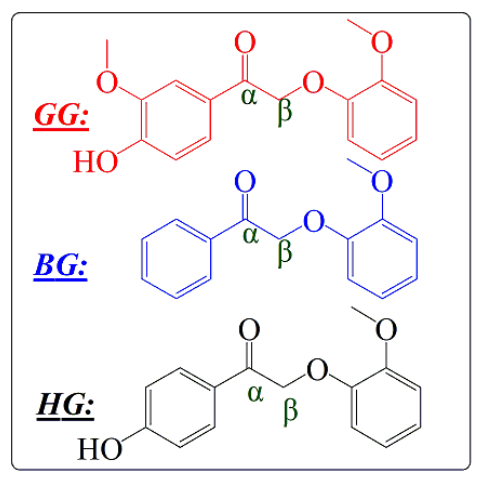

Fig. 1. The molecular structures of three $C_{\alpha}=O$ type model compounds. GG: 1-(4-hydroxy-3methoxy-phenyl)-2-(2-methoxy-phenoxy)-ethanone; BG: 2-(2-methoxy-phenoxy)-1-phenylethanone; HG: 1-(4-hydroxy-phenyl)-2-(2-methoxy-phenoxy)-ethanone

\section{EXPERIMENTAL}

\section{Materials}

Organic solvents, including methanol, ethyl acetate, petroleum ether, dichloromethane, and so on, were purchased from Aladdin Chemistry Co., Ltd. (Shanghai, China). The reactants, such as guaiacol, 2-bromo-1-phenyl-ethanone, 2-bromo-1-(4-hydroxylphenyl)-ethanone, 2-bromo-1-(4-hydroxyl-3-methoxy-phenyl)-ethanone, and so on, were purchased from Alfa Aesar Co. Inc. (Wuhan, China). All chemicals were used without further purification. The lignin model compounds (Fig. 1) were prepared according to the published methods (Zhao et al. 2018) and detailed data are shown in supplementary material. 


\section{Experimental Methods}

The thermal stability of three $\beta-\mathrm{O}-4$-type model compounds was analyzed using a simultaneous thermal analysis instrument (STA449 F3; NETZSCH, Germany). Approximately $10 \mathrm{mg}$ of sample was used for each test. The temperature was raised from room temperature to $650{ }^{\circ} \mathrm{C}$ under heating rates of $20{ }^{\circ} \mathrm{C} / \mathrm{min}$. The measurements were taken using high purity $\mathrm{N}_{2}$ with a protective gas flow rate of $25 \mathrm{~mL} / \mathrm{min}$ and a purge gas flow rate of $50 \mathrm{~mL} / \mathrm{min}$.

The in-situ diffuse reflectance infrared pyrolysis system used Fourier transform infrared spectroscopy (in-situ FTIR) (Nicolet IS50; Thermo Fisher Scientific Company, Waltham, MA, USA) and an in-situ pool with a deuterated sulfuric acid detector. To ensure full beam transmittance and good heat resistance, $\mathrm{CaF}_{2}$ with protective water-cooling was employed as the window. The real time temperature of the in-situ pool was adjusted using a temperature controller with a PID (proportion, integration, and differentiation) thermocoupling controller, and the accuracy of the temperature control was $\pm 1{ }^{\circ} \mathrm{C}$. Specific operation parameters were as follows: nitrogen with purity of $99.999 \%$ was used to purge the system at a rate of $1 \mathrm{~L} / \mathrm{min}$ for $15 \mathrm{~min}$ to maintain an inert atmosphere, after which the intake and outlet valves were closed to ensure that the pyrolysis process was carried out under sealed conditions. The temperature was increased from room temperature to $670{ }^{\circ} \mathrm{C}$ at a rate of $40{ }^{\circ} \mathrm{C} / \mathrm{min}$ and was held at $670{ }^{\circ} \mathrm{C}$ for $10 \mathrm{~min}$. The spectral scanning range was 650 to $4000 \mathrm{~cm}^{-1}$, the resolution was $4 \mathrm{~cm}^{-1}$, and the sampling interval was $1.93 \mathrm{~s}$. A N2 atmosphere at $100{ }^{\circ} \mathrm{C}$ was selected as the spectral background. The absence of interference from the purge gas on FTIR spectra of the pyrolysis vapors was ensured by a flat baseline corresponding to the beginning period.

Fast pyrolysis experiments of three dimers were conducted using a pyrolyzer (Tandem u-Reactor Rx-3050TR, Frontier Laboratories Ltd., Koriyama, Japan) having a direct connection to a gas chromatograph coupled with a mass spectrometer (GC/MS) (Agilent 7890B; Agilent Technologies, USA). In each experiment, $0.5 \mathrm{mg}$ dimer was placed in a quartz filler tube. The pyrolysis temperature was set from room temperature to different terminal temperatures of $400,450,500,550$, and $600{ }^{\circ} \mathrm{C}$ and a fixed residence time of $20 \mathrm{~s}$. The pyrolysis volatiles were analyzed online by GC/MS. The transfer line and injector temperature were kept at $300{ }^{\circ} \mathrm{C}$. The chromatographic separation was performed using a TR-5MS capillary column $(30 \mathrm{~m} \times 0.25 \mathrm{~mm}$ i.d., $0.25 \mu \mathrm{m}$ film thickness $)$. Helium (99.999\%) was used as the carrier gas with a constant flow rate of $1 \mathrm{~mL} / \mathrm{min}$ and a 1:80 split ratio. The oven temperature was programmed from $40{ }^{\circ} \mathrm{C}(3 \mathrm{~min})$ to $380{ }^{\circ} \mathrm{C}(3 \mathrm{~min})$ at the heating rate of $4{ }^{\circ} \mathrm{C} / \mathrm{min}$. The temperature of the $\mathrm{GC} / \mathrm{MS}$ interface was held at 300 ${ }^{\circ} \mathrm{C}$, and the mass spectrometer was operated in EI mode at $70 \mathrm{eV}$. The mass spectra were obtained from $\mathrm{m} / \mathrm{z} 20$ to 400 with the scan rate of $500 \mathrm{amu}^{-1}$. Identification of chromatographic peaks was achieved according to the retention time and by matching the mass spectrum with the standards in the spectral library. Each run was replicated three times, and then the average data was used to calculate the relative area and relative yields of products.

\section{RESULTS AND DISCUSSION}

\section{Thermal Stability Analysis}

The thermogravimetry (TG) and differential thermogravimetry (DTG) curves for the three $\beta-\mathrm{O}-4$-type lignin model compounds under $\mathrm{N}_{2}$ atmosphere at a heating rate of 20 
${ }^{\circ} \mathrm{C} / \mathrm{min}$ are shown in Fig. 2. At an early stage, ranging from room temperature to $150{ }^{\circ} \mathrm{C}$, a low weight loss was mainly attributed to moisture and organic solvent that was retained during synthesis. In the fast degradation stage, ranging from 150 to $400{ }^{\circ} \mathrm{C}$, most of the models were converted into volatiles. As determined from the DTG curves (Fig. 2b), the main weight loss peaks of $\mathrm{BG}, \mathrm{GG}$, and $\mathrm{HG}$ appeared at $245{ }^{\circ} \mathrm{C}, 308{ }^{\circ} \mathrm{C}$, and $320{ }^{\circ} \mathrm{C}$, respectively. For $\mathrm{HG}$ and GG, the main depolymerization stage was 200 to $400{ }^{\circ} \mathrm{C}$ and 200 to $350{ }^{\circ} \mathrm{C}$, respectively. The difference between $\mathrm{HG}$ and $\mathrm{GG}$ was substituent groups ($\mathrm{OCH}_{3}$ ) on the aromatic ring, suggesting that the $-\mathrm{OCH}_{3}$ on the aromatic rings enhanced the activity of the intermolecular linkages and decreased its thermal stability. Similar results were reported previously (Li et al. 2016; Zhao et al. 2018). In the slow degradation stage, the char yield of HG was approximately $10 \%$, which was higher than the char yields of GG and BG (approximately 2\%). In summary, substituent groups of aromatic rings had an effect on not only thermal stability of models, but also coke formation.
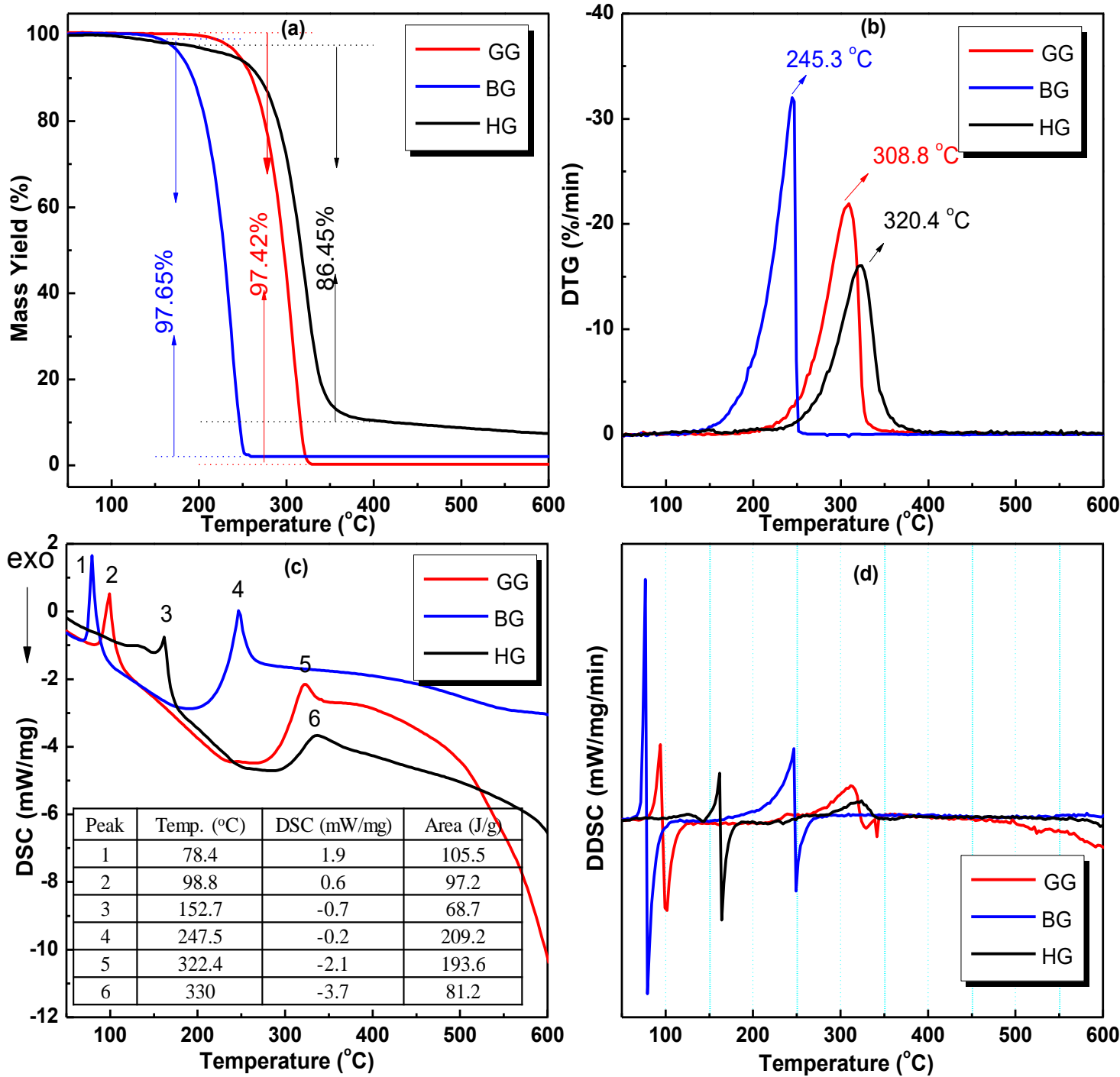

Fig. 2. TG, DTG, differential scanning calorimetry (DSC) and dynamic differential scanning calorimetry (DDSC) curves of three dimers 


\section{Main Functional Groups of Volatiles}

The FTIR spectra of pyrolysis volatiles at $500{ }^{\circ} \mathrm{C}$ and the assignments of spectral peaks are displayed in Fig. 3. Major functional group vibrations (Li et al. 2016; Jiang et al. 2017) were classified into the following nine categories. The real-time monitoring results of volatiles are visible in Fig. S2, showing the evolution of major functional groups occurred in the range of 200 to $400{ }^{\circ} \mathrm{C}$. It was in line with the mass loss result of TG, where the maximum weight loss rate temperature was $245{ }^{\circ} \mathrm{C}(\mathrm{BG}), 308{ }^{\circ} \mathrm{C}(\mathrm{GG})$, and $320{ }^{\circ} \mathrm{C}$ (HG).

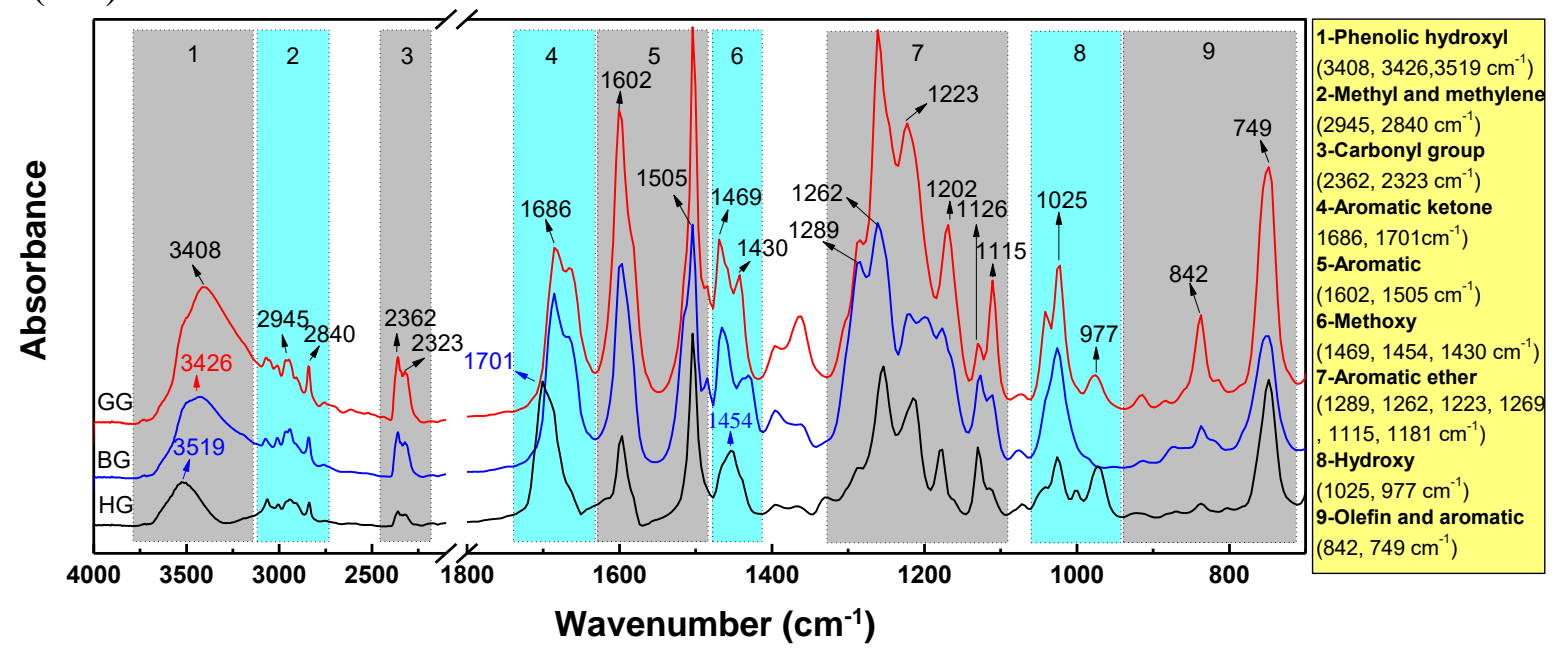

Fig. 3. FTIR spectra of three dimers at $500{ }^{\circ} \mathrm{C}$

Variation in absorption intensity of BG pyrolysis was monitored in real time and analyzed semi-quantitatively using the peak height (represented by blue line in Fig. S2). At the beginning, an increase involving alcoholic hydroxyl and methyl groups was found in Fig. S3 (a) and (d), it was speculated that small molecular alcohols (methyl alcohol) were released as a residual solvent. The absorption intensity of the carbonyl group grew rapidly between $250{ }^{\circ} \mathrm{C}$ and $400{ }^{\circ} \mathrm{C}$ and began to level off at higher temperatures $\left(>400{ }^{\circ} \mathrm{C}\right)$. This indicated that a large amount of volatile products with carbonyl groups were generated within the range 250 to $400{ }^{\circ} \mathrm{C}$, and the volatile products had relatively high stability during the whole pyrolysis process. Intramolecular hydrogen bond vibration of the phenolic hydroxyl functional groups at $3426 \mathrm{~cm}^{-1}, \mathrm{C}=\mathrm{C}$ stretching vibration of aromatic groups at $1602 \mathrm{~cm}^{-1}$, and $\mathrm{C}=\mathrm{O}$ stretching vibration of the aromatic ketone at $1686 \mathrm{~cm}^{-1}$ were first detected at $250{ }^{\circ} \mathrm{C}$, after which their intensity increased with pyrolysis temperature increase to $300{ }^{\circ} \mathrm{C}$. This was because the monomeric aromatics with phenolic $-\mathrm{OH}$ and $-\mathrm{COCH}_{3}$ groups were formed via the cleavage of the $\mathrm{C}_{\beta}-\mathrm{O}$ bond. With further temperature increases to $320{ }^{\circ} \mathrm{C}$, absorption intensity declined. The $-\mathrm{CH}_{3}$ group at $2362 \mathrm{~cm}^{-1}$ and $-\mathrm{CH}_{2}-$ at 2323 $\mathrm{cm}^{-1}$ were weak at low temperature, suggesting that the reaction involved the removal of methyl and methylene groups in aliphatic substructures was difficult. As to GG, variation in absorption intensity of specific functional groups is shown in Fig. S2 (represented by the red line). Intramolecular hydrogen bond vibration of the phenolic hydroxyl functional groups was detected from $230{ }^{\circ} \mathrm{C}$ that rapidly increased in intensity with temperature increase to $300{ }^{\circ} \mathrm{C}$, and then slowly increased. The peak corresponding to the emission of $\mathrm{C}=\mathrm{O}$, which appeared at approximately $300^{\circ} \mathrm{C}$, also increased in intensity with temperature. As compared to other models, its absorption intensity was higher, suggesting the higher yield. The peaks of methyl and methylene showed no changes before $200{ }^{\circ} \mathrm{C}$ and then they 
rapidly increased between 250 and $300{ }^{\circ} \mathrm{C}$. Liu et al. (2008) reported that $\mathrm{CH}_{4}$ was mainly attributed to the demethylation of methoxy $(-\mathrm{OCH} 3)$, methyl $\left(-\mathrm{CH}_{3}\right)$, and methylene ($\mathrm{CH}_{2}$ ) groups via homolytic cleavage of the $\mathrm{O}-\mathrm{CH}_{3}$ bond. It was suggested that the demethylation occurred in the range 200 to $300{ }^{\circ} \mathrm{C}$. In addition, the concentrations of methoxy, aromatic ketone, aromatic, aromatic ethers, and hydroxyl all increased between 250 and $300{ }^{\circ} \mathrm{C}$. This indicated that the cleavage of $\mathrm{C}_{\alpha}-\mathrm{C}_{\beta}$ and $\mathrm{C}_{\beta}-\mathrm{O}$ bonds mainly occurred between 250 and $300{ }^{\circ} \mathrm{C}$. This agreed with the maximum weight loss temperature range of GG. The absorbance intensity variation of HG with temperature is shown in Fig. S2, represented by black line. Almost all the change trend of absorption peaks was similar with GG and $\mathrm{BH}$. However, an obvious difference was that the absorption intensity was lower, especially for aromatic, carbon dioxide, carbon monoxide, and methyl and methylene groups. Such a finding indicated that the HG was more difficult to decompose compared with the GG and BG and produced less aromatics.

During the model compounds' pyrolysis, strong vibrations of aromatic rings at 1602 and $1505 \mathrm{~cm}^{-1}$ were evidence that aromatic compounds were the major pyrolysis products. The aromatic absorbance values of $\mathrm{BG}$ were nearly doubled compared to that of GG at 300 to $550{ }^{\circ} \mathrm{C}$, indicating that $\mathrm{BG}$ was converted into a higher concentration of aromatic monomeric products during pyrolysis. Combining with the TG data, where most of models were converted into volatiles, it can be speculated that adding the $-\mathrm{OCH}_{3}$ group to the ring was beneficial for promoting the formation of high molecular weight oligomer, and it led to the lower yield of aromatics. With increasing temperature, the peak value of aromatics reached maximum at $300{ }^{\circ} \mathrm{C}(\mathrm{GG}), 320^{\circ} \mathrm{C}(\mathrm{BG})$, and $265^{\circ} \mathrm{C}(\mathrm{HG})$. Then, there was a general decreasing tendency for the concentration within a shorter time period. The process was attributed to the secondary reaction of major monomeric aromatics. As the temperature continued to increase, the intensity gradually increased due to the pyrolysis of new oligomers at higher temperatures. The peak intensity corresponding to the aromatic ketone at 1686 and $1701 \mathrm{~cm}^{-1}$ and aromatic structures at 1602 and $1505 \mathrm{~cm}^{-1}$ was detected earlier than small molecular gas components $\left(\mathrm{CO}\right.$ and $\left.\mathrm{CO}_{2}\right)$. Such a result indicated that cleavage of intermolecular linkages dominated at low temperatures, followed by secondary reaction (Jiang et al. 2017). Additionally, aromatic ketones and aromatics, as the primary pyrolysis products, provided various gas and low-molecular-weight compounds. Just like the HG-type model compound, the peak corresponding to aromatic ketone at around 1701 $\mathrm{cm}^{-1}$ rapidly increased in intensity between 200 and $275^{\circ} \mathrm{C}$, slightly decreased after $275^{\circ} \mathrm{C}$, and at last leveled off. The absorbance values of the phenolic hydroxyl always increased in intensity between 200 and $350{ }^{\circ} \mathrm{C}$ and then gradually increased after $400{ }^{\circ} \mathrm{C}$. This suggested that phenolic hydroxyl groups were highly stable. In contrast, the intensity of the absorption involving to aromatic ketone, aromatics, methyl, and methylene grew rapidly between $250{ }^{\circ} \mathrm{C}$ and $300{ }^{\circ} \mathrm{C}$ and later declined before at last leveling off. This suggested that aromatic ketone, aromatics, and methyl and methylene groups could be transformed into downstream products by secondary reactions. In addition, the $\mathrm{CO}_{2}$ emission peak for the three samples was similar, beginning at approximately $300{ }^{\circ} \mathrm{C}$ and then intensifying with increasing temperature. This indicated that the decarboxylation reaction began at $300{ }^{\circ} \mathrm{C}$. However, the intensity of the $\mathrm{CO}_{2}$ absorption peak from GG was higher than $\mathrm{HG}$, suggesting that the methoxy group improved the level of decarboxylation.

\section{The Evolution of Pyrolytic Products During Fast Pyrolysis}

Representative pyrograms at $500{ }^{\circ} \mathrm{C}$ are shown in Fig. 4. Approximately 10 kinds of phenolic products or aromatic hydrocarbons with a high degree of matching (at least 
98\%) are listed in Tables 1 through 3. According to the aromatic substituent groups and the products origin, the detected compounds were divided into three categories (Fig. S4): (1) Ring A products (RAP), i.e., benzaldehyde, acetophenone, vanillin, acetovanillone, 4hydroxy-benzaldehyde, and 4-hydroxy-acetophenone; (2) Ring B products (RBP), i.e., guaiacol and 2-methoxy-benzaldehyde; (3) RAP and RBP derivatives (RD), including phenol, 2-methylphenol, 4-methylphenol, etc. Based on Py-GC/MS, the evolution of content for RAP, RBP, RD is shown in Fig. 5(a), Fig. 5(b), and Fig. 6, respectively.

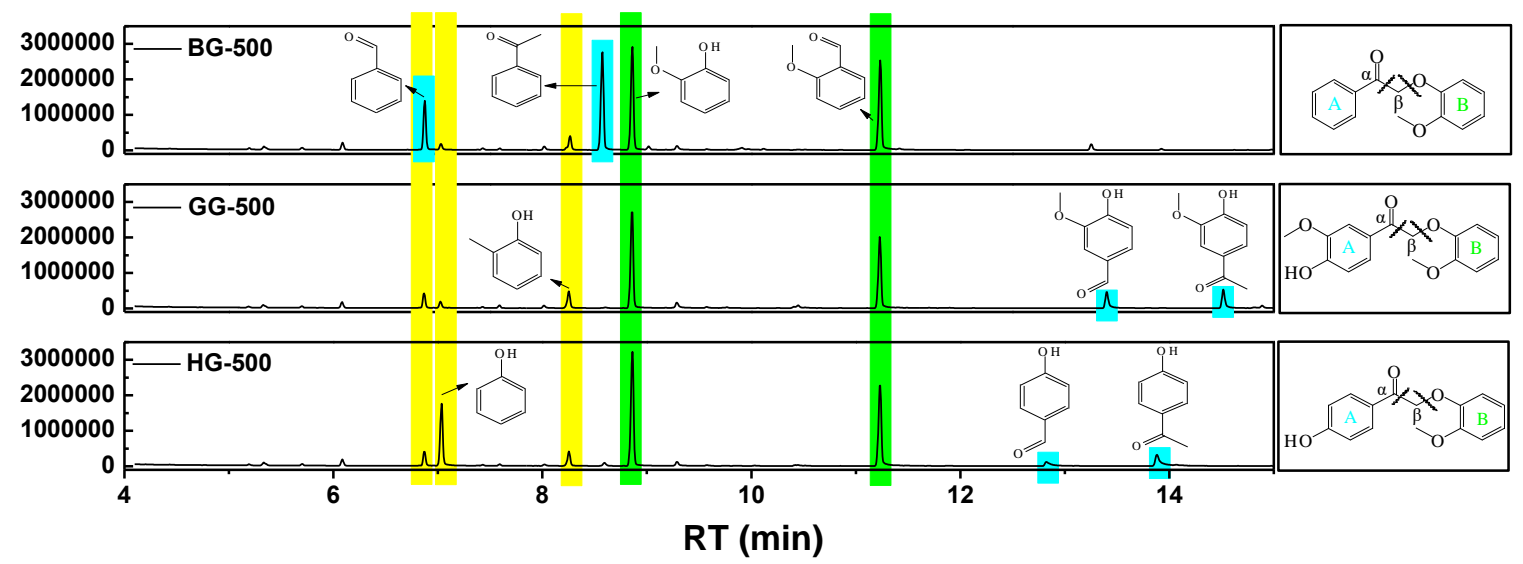

Fig. 4. GC-MS chromatogram of three models obtained at $500^{\circ} \mathrm{C}$

As shown in Table 1, the main pyrolysis products of $\mathrm{BH}$ were benzaldehyde, phenol, 2-methylphenol, acetophenone, guaiacol, and 2-methoxy-benzaldehyde. Among these, $\mathrm{RBP}$, obtained via the cleavage of $\mathrm{C}_{\beta}-\mathrm{O}$ bonds, predominated at low temperatures $\left(400{ }^{\circ} \mathrm{C}\right)$, and the total relative content was $57.5 \%$.

Table 1. Distribution of Main Pyrolytic Products from the BG Under Different Temperatures (Amount in Relative area (\%))

\begin{tabular}{|c|c|c|c|c|c|c|c|}
\hline \multirow{2}{*}{ NO. } & \multirow{2}{*}{ Compounds } & \multirow{2}{*}{$\mathrm{RT}(\mathrm{min})$} & \multicolumn{5}{|c|}{ Pyrolysis Temperature $\left({ }^{\circ} \mathrm{C}\right)$} \\
\cline { 5 - 8 } & & & 400 & 450 & 500 & 550 & 600 \\
\hline 5 & Benzaldehyde & 6.87 & 5.0 & 7.4 & 9.7 & 10.0 & 10.3 \\
\hline 6 & Phenol & 7.03 & 0.4 & 0.5 & 1.2 & 3.8 & 5.2 \\
\hline 11 & $2-$ Methylphenol & 8.27 & 0.0 & 0.5 & 3.3 & 8.0 & 8.3 \\
\hline 12 & Acetophenone & 8.58 & 14.6 & 16.9 & 21.5 & 27.1 & 32.0 \\
\hline 13 & 8.86 & 30.0 & 27.9 & 22.3 & 9.6 & 6.0 \\
\hline 24 & Guaiacol & 11.23 & 27.5 & 24.0 & 21.2 & 13.2 & 8.9 \\
\hline \multicolumn{2}{|c|}{ 2-Methoxy-benzaldehyde } & & 77.5 & 77.2 & 79.2 & 71.5 & 70.6 \\
\hline
\end{tabular}



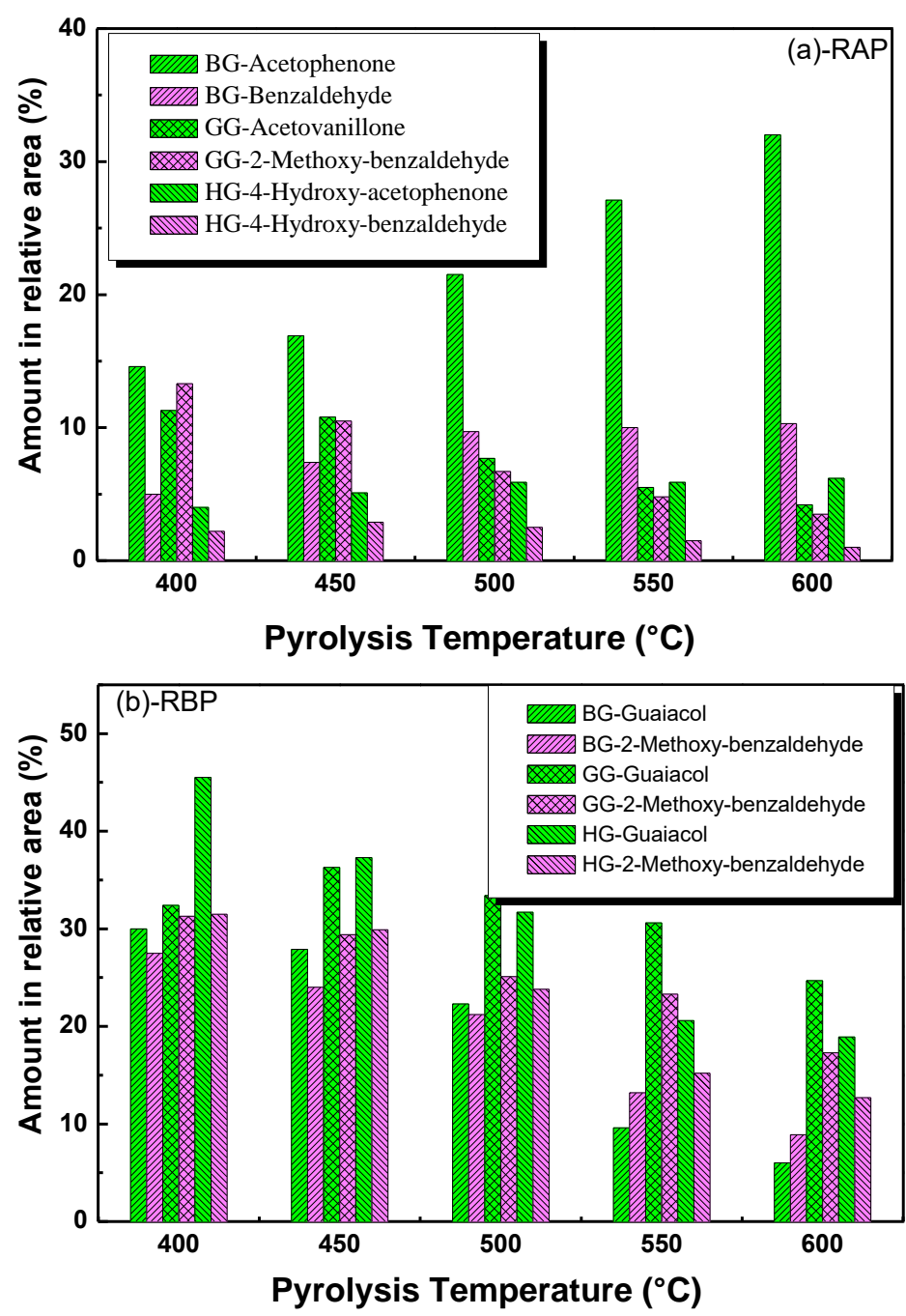

Fig. 5. The evolution of content for several selected components from ring $A$ and $B$ based on the results of Py-GCMS

The most representative compounds were guaiacol and 2-methoxy-benzaldehyde, with peak areas (\%) of $30.0 \%$ and $27.5 \%$, respectively. Additionally, benzaldehyde and 2methoxy-benzaldehyde, as RAP, was the product of ring A via the cleavage of $\mathrm{C}_{\alpha}-\mathrm{C}_{\beta}$ bond, and had the second highest peak areas (\%) of approximately $20 \%$ at $400{ }^{\circ} \mathrm{C}$. Based on the previous "Thermal Stability Analysis" and "Main Functional Groups of Volatiles" experimental data, and the result of Py-GC/MS where no models samples were detected, it can be verified that BG was decomposed completely at $400{ }^{\circ} \mathrm{C}$. In other words, RAP and $\mathrm{RBP}$ were generally originated from the direct splitting of the ring $\mathrm{A}$ and $\mathrm{B}$ unit via the cleavage of $\mathrm{C}_{\alpha}-\mathrm{C}_{\beta}$ and $\mathrm{C}_{\beta}-\mathrm{O}$ bonds of the $\mathrm{BG}$ structure at $400{ }^{\circ} \mathrm{C}$. In addition, RD generally originated from the secondary cracking reactions, and its concentrations were lowest at $400{ }^{\circ} \mathrm{C}$, as compared to RAP and RBP.

As shown in Fig. 5, phenol was detected as a representative RD at $400{ }^{\circ} \mathrm{C}$ at only $0.4 \%$. It was likely formed via the transformation of RBP. As temperatures increased from $400{ }^{\circ} \mathrm{C}$ to $600{ }^{\circ} \mathrm{C}$, RBP decreased rapidly, while RAP and RD increased. For example, guaiacol and 2-methoxy-benzaldehyde decreased from $30.0 \%$ and $27.5 \%$ to $6.0 \%$ and $8.9 \%$, respectively. Meanwhile, benzaldehyde and acetophenone increased from $5.0 \%$ and $14.6 \%$ to $10.3 \%$ and $32.0 \%$, respectively. 


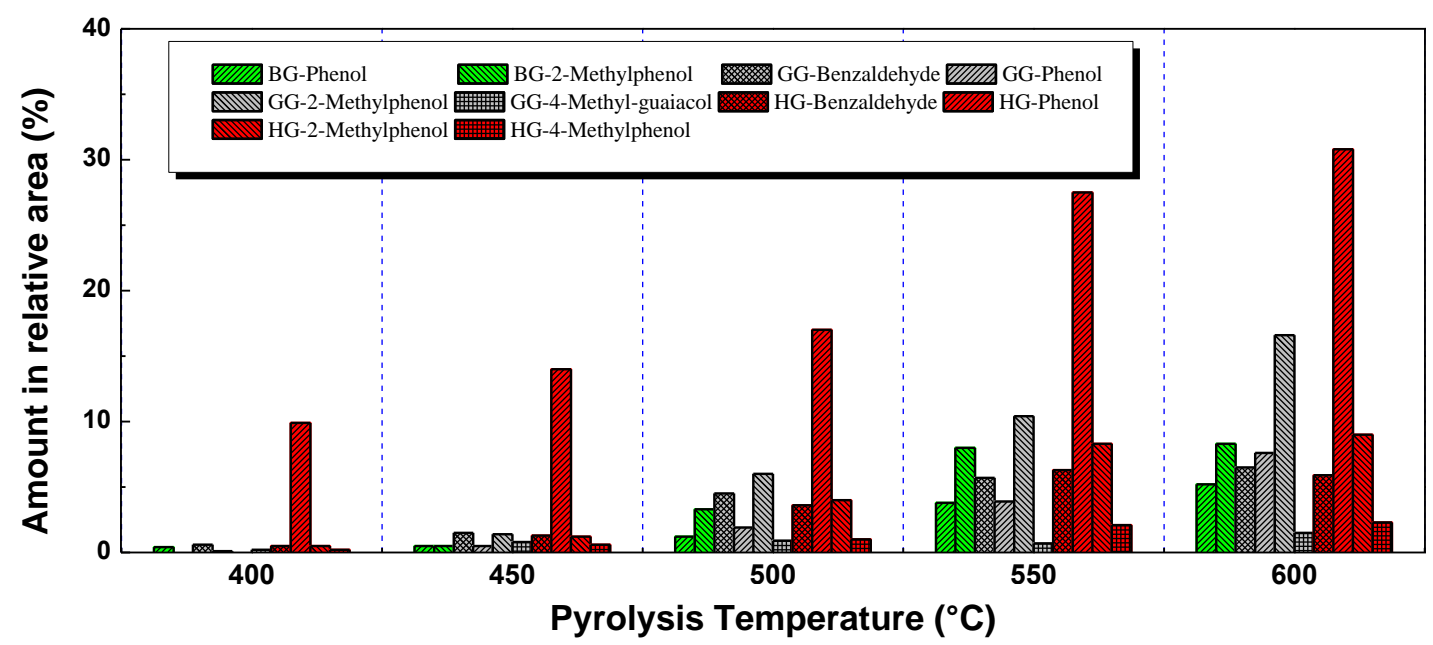

Fig. 6. The evolution of content for several secondary reaction components based on the results of Py-GCMS

As temperatures increase to $600{ }^{\circ} \mathrm{C}$, RAP became the main compounds, and the total peak area could come up to $42.3 \%$. Particularly, acetophenone, as a representative RAP, had a concentration of $32.0 \%$. In addition, 2-methylphenol, as a representative RD like phenol, was first detected at $450{ }^{\circ} \mathrm{C}$. Its yield increased to $8.3 \%$ at $600{ }^{\circ} \mathrm{C}$. This suggested that more products occurred in secondary reactions, and the intensity was increasingly stronger with pyrolysis temperature increase.

Table 2 shows that the main pyrolytic products from the GG were vanillin (13.3\%), acetovanillone (11.3\%), guaiacol (32.4\%), and 2-methoxy-benzaldehyde $(31.3 \%)$ at 400 ${ }^{\circ} \mathrm{C}$. It was clear that four compounds were formed via the cleavage of $\mathrm{C}_{\alpha}-\mathrm{C}_{\beta}$ and $\mathrm{C}_{\beta}-\mathrm{O}$ bonds and not secondary reactions. The result indicated that four pyrolysis products sustained a fine stability at low temperature. When the temperature increased to $600{ }^{\circ} \mathrm{C}$, the content of 2-methoxy-benzaldehyde, vanillin, and acetovanillone decreased to $17.3 \%$, $3.5 \%$, and $4.2 \%$, respectively.

Meanwhile, RD (benzaldehyde, phenol, 2-methylphenol, and 4-methyl-guaiacol) increased, particularly 2-methylphenol, and it increased to $16.6 \%$. It had been reported that 2-methylphenol was converted by guaiacol, which occurred after the rearrangement of aryl- $\mathrm{OCH}_{3}$ into aryl- $\mathrm{CH}_{3}$ structure. Additionally, guaiacol had a higher proportion compared to that from BG. Based on the above result, it was speculated that vanillin and acetovanillone were unstable during the pyrolysis process, and both might play an important role on the formation of guaiacol, 2-methylphenol, and 4-methyl-guaiacol via side-chain-conversion. Hence, data on thermal reactivity and secondary pyrolysis pathways of vanillin and acetovanillone was also studied via in-situ FTIR within a tube furnace reactor system (Jiang et al. 2018). The result indicated that vanillin had higher reactivity than acetovanillone. The removal of the $-\mathrm{CHO}$ group in vanillin was observed at $400{ }^{\circ} \mathrm{C}$. Overall, guaiacol could have been obtained via the cleavage of $\mathrm{C}_{\beta}-\mathrm{O}$ bonds and also through removal of $-\mathrm{CHO}$ from vanillin. 
Table 2. Distribution of Main Pyrolytic Products from the GG Under Different Temperatures (Amount in Relative Area (\%))

\begin{tabular}{|c|c|c|c|c|c|c|c|}
\hline \multirow{2}{*}{ No. } & \multirow{2}{*}{ Compounds } & \multirow{2}{*}{$\mathrm{RT}$ (min) } & \multicolumn{5}{|c|}{ Pyrolysis Temperature $\left({ }^{\circ} \mathrm{C}\right)$} \\
\hline & & & 400 & 450 & 500 & 550 & 600 \\
\hline 5 & Benzaldehyde & 6.87 & 0.6 & 1.5 & 4.5 & 5.7 & 6.5 \\
\hline 6 & Phenol & 7.04 & 0.1 & 0.5 & 1.9 & 3.9 & 7.6 \\
\hline 11 & 2-Methylphenol & 8.25 & 0.0 & 1.4 & 6.0 & 10.4 & 16.6 \\
\hline 14 & Guaiacol & 8.87 & 32.4 & 36.3 & 33.4 & 30.6 & 24.7 \\
\hline 20 & 4-Methyl-guaiacol & 10.45 & 0.2 & 0.8 & 0.9 & 0.7 & 1.5 \\
\hline 23 & 2-Methoxy-benzaldehyde & 11.24 & 31.3 & 29.4 & 25.1 & 23.3 & 17.3 \\
\hline 25 & Vanillin & 13.41 & 13.3 & 10.5 & 6.7 & 4.8 & 3.5 \\
\hline 28 & Acetovanillone & 14.52 & 11.3 & 10.8 & $\begin{array}{ll}7.7 \\
\end{array}$ & 5.5 & 4.2 \\
\hline \multicolumn{3}{|c|}{ Total peak area percentage } & 89.0 & 90.5 & 85.4 & 84.1 & 80.5 \\
\hline
\end{tabular}

Table 3. Distribution of Main Pyrolytic Products from the HG Under Different Temperatures (Amount in Relative Area (\%))

\begin{tabular}{|c|c|c|c|c|c|c|c|}
\hline \multirow{2}{*}{ No. } & \multirow{2}{*}{ Compounds } & \multirow{2}{*}{$\mathrm{RT}(\min )$} & \multicolumn{5}{|c|}{ Pyrolysis Temperature $\left({ }^{\circ} \mathrm{C}\right)$} \\
\hline & & & 400 & 450 & 500 & 550 & 600 \\
\hline 5 & Benzaldehyde & 6.87 & 0.5 & 1.3 & 3.6 & 6.3 & 5.9 \\
\hline 6 & Phenol & 7.04 & 9.9 & 14.0 & 17.0 & 27.5 & 30.8 \\
\hline 11 & 2-Methylphenol & 8.26 & 0.5 & 1.2 & 4.0 & 8.3 & 9.0 \\
\hline 12 & 4-Methylphenol & 8.59 & 0.2 & 0.6 & 1.0 & 2.1 & 2.3 \\
\hline 13 & Guaiacol & 8.86 & 45.5 & 37.3 & 31.7 & 20.6 & 18.9 \\
\hline 24 & 2-Methoxy-benzaldehyde & 11.23 & 31.5 & 29.9 & 23.8 & 15.2 & 12.7 \\
\hline 30 & 4-Hydroxy-benzaldehyde & 12.85 & 2.2 & 2.9 & 2.5 & 1.5 & 1.0 \\
\hline 33 & 4-Hydroxy-acetophenone & 13.89 & 4.0 & 5.1 & 5.9 & 5.9 & 6.2 \\
\hline \multicolumn{3}{|c|}{ Total peak area percentage } & 94.4 & 92.1 & 89.5 & 87.3 & 86.8 \\
\hline
\end{tabular}

As to HG, the main pyrolysis products (Table 3) included phenol, guaiacol, and 2methoxy-benzaldehyde at $400{ }^{\circ} \mathrm{C}$. Similar to the BG and GG type model compound, 2methoxy-benzaldehyde and guaiacol were also two important products from Ring $\mathrm{B}$ via the cleavage of $\mathrm{C}_{\beta}-\mathrm{O}$ and $\mathrm{C}_{\alpha}-\mathrm{C}_{\beta}$ bonds, whose yield were $45.5 \%$ and $31.5 \%$ at $400{ }^{\circ} \mathrm{C}$, respectively. As the typical RAP-type pyrolysis products, 4-hydroxy-benzaldehyde and 4hydroxy-acetophenone were only $2.2 \%$ and $4.0 \%$, respectively, which indicated that RAP might play an important role on polymerization and side-chain-conversion during the pyrolysis process. Meanwhile, phenol $(9.9 \%)$ was detected at $400{ }^{\circ} \mathrm{C}$, and it was different from the pyrolysis product distribution for $\mathrm{BG}$ and $\mathrm{HG}$. Based on the structure characteristics of the product, it was deduced that phenol could be obtained via many kinds of secondary reaction pathways. As described in the previous section, guaiacol could be an important precursor, and it was in the habit of removal of $-\mathrm{OCH}_{3}$ for formation of phenol at higher temperature. In addition, the removal of the - $\mathrm{CHO}$ group from 4-hydroxybenzaldehyde could be another reason. When the temperature increased to $600{ }^{\circ} \mathrm{C}$, the percentage of 4-hydroxy-benzaldehyde was only $1.0 \%$. Meanwhile, the yield of phenol increased to $30.8 \%$, and it was higher than that of BG $(0.4 \%)$ and GG $(0.1 \%)$. This meant that most of the removal of - $\mathrm{CHO}$ from 4-hydroxy-benzaldehyde occurred at $600{ }^{\circ} \mathrm{C}$. 
Hence, the - CHO removal of 4-hydroxy-benzaldehyde was considered to be the dominating pathway for phenol formation.

In summary, oxidization of benzylic alcohol $\left(\mathrm{C}_{\alpha}-\mathrm{OH}\right)$ to benzylic ketone $\left(\mathrm{C}_{\alpha}=\mathrm{O}\right)$ not only facilitated the cleavage of $\mathrm{C}_{\alpha}-\mathrm{O}$ and $\mathrm{C}_{\alpha}-\mathrm{C}_{\beta}$ bonds (Jiang et al. 2018), but it also simplified depolymerization pathways, resulting in better selectivity of phenolic monomers and a predictable product distribution. Generally, the pyrolysis process included primary and secondary reactions (Scholze and Meier 2001). As shown in Figs. 4 and 5, monomeric compounds RAP and RBP are regarded as primary products derived directly from pyrolysis and are also regarded as the intermediates that occur in the secondary reactions for the formation of RD due to substituted groups and aromatic nucleus. Affected by the substituents, primary products showed different reaction activity. For instance, RAP (benzaldehyde and acetophenone) were the typical products of ring $\mathrm{A}$ via the direct cleavage of the $\mathrm{C}_{\beta}-\mathrm{O}$ and $\mathrm{C}_{\alpha}-\mathrm{C}_{\beta}$ bond. The high stability at 400 to $600{ }^{\circ} \mathrm{C}$ and the peak area ratio of benzaldehyde and acetophenone could reflect the cleavage ratio of $\mathrm{C}_{\alpha}-\mathrm{C}_{\beta}$ and $\mathrm{C}_{\beta}-\mathrm{O}$ bonds. During the pyrolysis process, the cleavage ratio of the $\mathrm{C}_{\beta}-\mathrm{O}$ was 68 to $76 \%$, which indicated that the cleavage of the $\mathrm{C}_{\beta}-\mathrm{O}$ bond was primary compared with that of $\mathrm{C}_{\alpha}-\mathrm{C}_{\beta}$. This is mainly because the dissociation energy of $\mathrm{C}_{\beta}-\mathrm{O}$ was lower than that of $\mathrm{C}_{\alpha-}$ $\mathrm{C}_{\beta}$; therefore, the homolytic cleavage of $\mathrm{C}_{\beta}-\mathrm{O}$ bonds dominated over the $\mathrm{C}_{\alpha}-\mathrm{C}_{\beta}$ homolytic reactions in the pyrolysis process (Britt et al. 2000). Meanwhile, guaiacol and 2-methoxybenzaldehyde, as RBP, were also important products from primary reaction. Guaiacol mainly was formed through combination of the guaiacyl radical with free $\mathrm{H}$ radicals after $\mathrm{C}_{\beta}-\mathrm{O}$ homolytic reaction (Li et al. 2016; Zhu et al. 2016). During the $\mathrm{C}_{\alpha}-\mathrm{C}_{\beta}$ homolytic reactions (Jiang et al. 2017), 2-methoxy-benzaldehyde was obtained through a series of reactions after breaking the $\mathrm{C}_{\alpha}-\mathrm{C}_{\beta}$ bond, and the optimized geometries of reactants, intermediates, transition states, and products in pyrolysis processes had been reported in previous literature (Yanez et al. 2018). Based on the product's structure, guaiacol and 2methoxy-benzaldehyde were considered as two important intermediates that can occur in the secondary reactions. Phenol and 2-methylphenol were the typical downstream products and were converted via secondary reactions of RBP. A schematic diagram of the proposed mechanism of guaiacol and 2-methoxy-benzaldehyde is shown in Fig. S5. At low pyrolysis temperature, guaiacol can convert into phenol through the release of $-\mathrm{OCH}_{3}$. At higher pyrolysis temperatures guaiacol was converted into 2-methylphenol via radical-induced rearrangement of the aryl- $\mathrm{OCH}_{3}$ group into the aryl $-\mathrm{CH}_{3}$ group. The aryl- $\mathrm{OCH}_{3}$ group into the aryl- $\mathrm{CH}_{3}$ group was more competitive than the removal of $-\mathrm{OCH}_{3}$. For $\mathrm{GG}$ and HG model compounds, the secondary reaction of RBP (guaiacol and 2-methoxybenzaldehyde) was in agreement with BG. However, affected by the substituents (phenolic hydroxyl and methoxy), RAP showed higher reaction activity.

\section{CONCLUSIONS}

1. Substituent groups of aromatic rings had an effect on thermal stability of model compounds, emission of volatiles, and the evolution of pyrolytic products. Particularly, the $-\mathrm{OCH}_{3}$ on the aromatic rings played an important role for enhancing the activity of the intermolecular linkages and decreasing its thermal stability.

2. Pyrolysis of pre-oxidized $\beta$-ether-type lignin models mainly included two pathways: (a) cleavage of $\mathrm{C}_{\alpha}-\mathrm{C}_{\beta}$ and $\mathrm{C}_{\beta}-\mathrm{O}$ bonds; and (b) secondary pyrolysis of monomeric 
aromatics. Oxidation of the $\mathrm{C}_{\alpha}-\mathrm{OH}$ group into $\mathrm{C}_{\alpha}=\mathrm{O}$ could effectively curb the formation of new dimers, resulting in better selectivity of phenolic monomers and a predictable product distribution.

3. Volatile products mainly included large amounts of guaiacol and 2-methoxybenzaldehyde and their derived aromatics. Among these, guaiacol and 2-methoxybenzaldehyde were two important intermediates, and secondary reactions mainly occurred via the rearrangement and removal of aryl- $-\mathrm{OCH}_{3}$.

\section{ACKNOWLEDGMENTS}

This work was supported by National Natural Science Foundation of China (Nos. 31901266 and 31770626) and the Foundation (No. ZZ20190101) of State Key Laboratory of Bio-based Material and Green Papermaking, Qilu University of Technology, Shandong Academy of Sciences.

\section{REFERENCES CITED}

Boerjan, W., Ralph, J., and Baucher, M. (2003). "Lignin biosynthesis," Annual Review of Plant Biology 54(1), 519-546. DOI: 10.1146/annurev.arplant.54.031902.134938

Britt, P. F., Buchanan, A. C., Cooney, M. J., and Martineau, D. R. (2000). "Flash vacuum pyrolysis of methoxy-substituted lignin model compounds," Journal of Organic Chemistry 65(5), 1376-1389. DOI: 10.1021/jo991479k

Chen, L., Ye, X., Luo, F., Shao, J., Lu, Q., Fang, Y., Wang, X., and Chen, H. (2015). "Pyrolysis mechanism of $\beta-\mathrm{O}-4$ type lignin model dimer," Journal of Analytical and Applied Pyrolysis 115, 103-111. DOI: 10.1016/j.jaap.2015.07.009

Chen, W. H., and Kuo, P. C. (2011). "Torrefaction and co-torrefaction characterization of hemicellulose, cellulose and lignin as well as torrefaction of some basic constituents in biomass," Energy 36(2), 803-811. DOI: 10.1016/j.energy.2010.12.036

Crestini, C., Lange, H., Sette, M., and Argyropoulos, D. S. (2017). "On the structure of softwood kraft lignin," Green Chemistry 19(17), 4104-4121. DOI: 10.1039/C7GC01812F

Farag, S., and Chaouki, J. (2015). "Economics evaluation for on-site pyrolysis of kraft lignin to value-added chemicals," Bioresource Technology 175, 254-261. DOI: 10.1016/j.biortech.2014.10.096

Han, T., Sophonrat, N., Evangelopoulos, P., Persson, H., Yang, W. H., and Jonsson, P. (2018). "Evolution of sulfur during fast pyrolysis of sulfonated Kraft lignin," Journal of Analytical and Applied Pyrolysis 133, 162-168. DOI: 10.1016/j.jaap.2018.04.006

Jiang, W. K., Wu, S. B., Lucia, L. A., and Chu, J. Y. (2017). "A comparison of the pyrolysis behavior of selected $\beta$-O-4 type lignin model compounds," Journal of Analytical and Applied Pyrolysis 125, 185-192. DOI: 10.1016/j.jaap.2017.04.003

Jiang, W. K., Chu, J. Y.,Wu, S. B., and Lucia, L. A. (2018a). "Modeling pyrolytic behavior of pre-oxidized lignin using four representative $\beta$-ether-type lignin-like model polymers," Fuel Processing Technology 176, 221-229. DOI: 10.1016/j.fuproc.2018.03.041 
Jiang, W. K., Chu, J. Y., Wu, S. B., and Lucia, L. A. (2018b). "Modeling the pyrolytic behavior of lignin through two representative monomers: Vanillin and acetovanillone," Journal of Analytical and Applied Pyrolysis 130, 241-248. DOI: 10.1016/j.jaap.2018.01.001

Kawamoto, H. (2017). "Lignin pyrolysis reactions," Journal of Wood Science 63(2), 117132. DOI: $10.1007 / \mathrm{s} 10086-016-1606-\mathrm{Z}$

Kawamoto, H., Horigoshi, S., and Saka, S. (2007a). "Effects of side-chain hydroxyl groups on pyrolytic $\beta$-ether cleavage of phenolic lignin model dimer," Journal of Wood Science 53(3), 268-271. DOI: 10.1007/s10086-006-0839-7

Kawamoto, H., Horigoshi, S., and Saka, S. (2007b). "Pyrolysis reactions of various lignin model dimers," Journal of Wood Science 53(2), 168-174. DOI: 10.1007/s10086-0060834-z

Kawamoto, H., Ryoritani, M., and Saka, S. (2008). "Different pyrolytic cleavage mechanisms of $\beta$-ether bond depending on the side-chain structure of lignin dimers," Journal of Analytical and Applied Pyrolysis 81(1), 88-94. DOI:

10.1016/j.jaap.2007.09.006

Kawamoto, H., and Saka, S. (2017). "Role of side-chain hydroxyl groups in pyrolytic reaction of phenolic $\beta$-ether type of lignin dimer," Journal of Wood Chemistry \& Technology 27(2), 113-120. DOI: 10.1080/02773810701515119

Klein, M. T. (1983). "Model pathways in lignin thermolysis," Industrial \& Engineering Chemistry Research 22(1), 35-45. DOI: 10.1021/i100009a007

Li, C. Z., Zhao, X. C., Wang, A. Q., Huber, G. W., and Zhang, T. (2015). "Catalytic transformation of lignin for the production of chemicals and fuels," Chemical Reviews 115(21), 11559-11624. DOI: 10.1021/acs.chemrev.5b00155

Li, P., Chen, L., Wang, X., Yang, H., Shao, J., and Chen, H. (2016). "Effects of oxygencontaining substituents on pyrolysis characteristics of $\beta-\mathrm{O}-4$ type model compounds," Journal of Analytical and Applied Pyrolysis 120, 52-59. DOI:

10.1016/j.jaap.2016.04.009

Liu, Q., Wang, S., Zheng, Y., Luo, Z., and Cen, K. (2008). "Mechanism study of wood lignin pyrolysis by using TG-FTIR analysis," Journal of Analytical and Applied Pyrolysis 82(1), 170-177. DOI: 10.1016/j.jaap.2008.03.007

Lohr, T. L., Li, Z., and Marks, T. J. (2015). "Selective ether/ester C-O cleavage of an acetylated lignin model via tandem catalysis," ACS Catalysis 5(11), 7004-7007. DOI: $10.1021 /$ acscatal.5b01972

No, S. Y. (2014). "Application of bio-oils from lignocellulosic biomass to transportation, heat and power generation-A review," Renewable \& Sustainable Energy Reviews 40, 1108-1125. DOI: 10.1016/j.rser.2014.07.127

Ong, H. C., Chen, W. H., Farooq, A., Gan, Y. Y., Lee, K. T., and Ashokkumar, V. (2019). "Catalytic thermochemical conversion of biomass for biofuel production: A comprehensive review," Renewable \& Sustainable Energy Reviews 113(109266), 116. DOI: $10.1016 /$ j.rser.2019.109266

Ralph, J., Lapierre, C., and Boerjan, W. (2019). "Lignin structure and its engineering," Current Opinion in Biotechnology 56, 240-249. DOI: 10.1016/j.copbio.2019.02.019

Scholze, B., and Meier, D. J. (2001). "Characterization of the water-insoluble fraction from pyrolysis oil (pyrolytic lignin). Part I. PY-GC/MS, FTIR, and functional groups," Journal of Analytical and Applied Pyrolysis 60(1), 41-54. DOI: 10.1016/S0165-2370(00)00110-8 
Wang, S., Ru, B., Dai, G., Shi, Z., Zhou, J., Luo, Z., Ni, M., and Cen, K. (2016). "Mechanism study on the pyrolysis of a synthetic $\beta-\mathrm{O}-4$ dimer as lignin model compound," Proceedings of the Combustion Institute 36(2), 2225-2233. DOI: 10.1016/j.proci.2016.07.129

Watanabe, T., Kawamoto, H., and Saka, S. (2015). "Pyrolytic reactivities of deuterated $\beta$ ether-type lignin model dimers," Journal of Analytical and Applied Pyrolysis 112, 2328. DOI: 10.1016/j.jaap.2015.02.028

Yanez, A. J., Natarajan, P., Li, W., Mabon, R., and Broadbelt, L. J. (2018). “Coupled structural and kinetic model of lignin fast pyrolysis," Energy and Fuels 32(2), 1822 1830. DOI: 10.1021/acs.energyfuels.7b03311

Zhang, C., Li, H., Lu, J., Zhang, X., MacArthur, K. E., Heggen, M., and Wang, F. (2017). "Promoting lignin depolymerization and restraining the condensation via an oxidation-hydrogenation strategy," ACS Catalysis 7(5), 3419-3429. DOI: 10.1021/acscatal.7b00148

Zhao, L., Shi, S., Liu, M., Zhu, G., Wang, M., Du, W., Gao, J., and Xu, J. (2018). "Covalent triazine frameworks catalytically oxidative cleavage of lignin models and organosolv lignin," Green Chemistry 20(6), 1270-1279. DOI: 10.1039/C8GC00268A

Zhu, G. D., Qiu, X. Q., Zhao, Y., Qian, Y., Pang, Y. X., and Ouyang, X. P. (2016). "Depolymerization of lignin by microwave-assisted methylation of benzylic alcohols," Bioresource Technology 218, 718-722. DOI:

10.1016/j.biortech.2016.07.021

Article submitted: April 28, 2020; Peer review completed: July 3, 2020; Revised version received and accepted: July 19, 2020; Published: July 23, 2020.

DOI: 10.15376/biores.15.3.6989-7008 


\section{SUPPLEMENTARY MATERIAL}

Three types of model dimers were used in this study, and detailed data are shown below: (1) 1-(4-hydroxy-3-methoxy-phenyl)-2-(2-methoxy-phenoxy)-ethanone, referred to as GG; (2) 2-(2-methoxy-phenoxy)-1-phenyl-ethanone, referred to as BG; (3) 1-(4hydroxy-phenyl)-2-(2-methoxy-phenoxy)-ethanone, referred to as HG. The chemical structures were confirmed by ${ }^{1} \mathrm{H}$ NMR and ${ }^{13} \mathrm{C}$ NMR.

GG: ${ }^{1} \mathrm{H}$ NMR (600 MHz, DMSO-d6) $\delta 10.11(\mathrm{~s}, 1 \mathrm{H}$, aryl-OH), 7.59 to $6.80(\mathrm{~m}$, $7 \mathrm{H}), 5.43(\mathrm{~s}, 2 \mathrm{H}), 3.84$ to $3.78(\mathrm{~m}, 6 \mathrm{H}) ;{ }^{13} \mathrm{C} \mathrm{NMR}(151 \mathrm{MHz}, \mathrm{DMSO}-\mathrm{d} 6) \delta 193.21\left(\mathrm{C}_{\alpha}\right)$, $152.72,149.45,148.12,148.04,126.70,123.36,121.72,121.01,115.56,114.10,112.94$, 111.65 (aryl C), $70.90\left(\mathrm{C}_{\beta}\right), 56.14,56.03\left(-\mathrm{OCH}_{3}\right)$.

BG: ${ }^{1} \mathrm{H}$ NMR (600 MHz, DMSO-d 6$) \delta 8.03(\mathrm{~m}, 2 \mathrm{H}), 7.69(\mathrm{~m}, 1 \mathrm{H}), 7.57$ (m, 2H), 6.99 to $6.81(\mathrm{~m}, 4 \mathrm{H}), 5.54(\mathrm{~s}, 2 \mathrm{H}), 3.78(\mathrm{~s}, 3 \mathrm{H}) ;{ }^{13} \mathrm{C}$ NMR (151 MHz, DMSO-d $) \delta 194.6$, 149.9, 147.6, 134.7, 128.8, 128.2, 122.6, 120.9, 115, 112.3, 72.2,56.

HG: ${ }^{1} \mathrm{H}-\mathrm{NMR}\left(600 \mathrm{MHz}, \mathrm{DMSO}-\mathrm{d}_{6}\right): 10.46(\mathrm{~s}, 1 \mathrm{H}), 7.91$ to approximately $6.79(\mathrm{~m}$, 8H), 5.40 (s, 2H), 3.78 (s, 3H); ${ }^{13} \mathrm{C}-\mathrm{NMR}$ (151 MHz, DMSO-d $)$ ): 193.16, 162.99, 149.50, $148.09,130.96,126.55,121.75,121.04,115.84,114.19,113.03,70.90,56.08$.

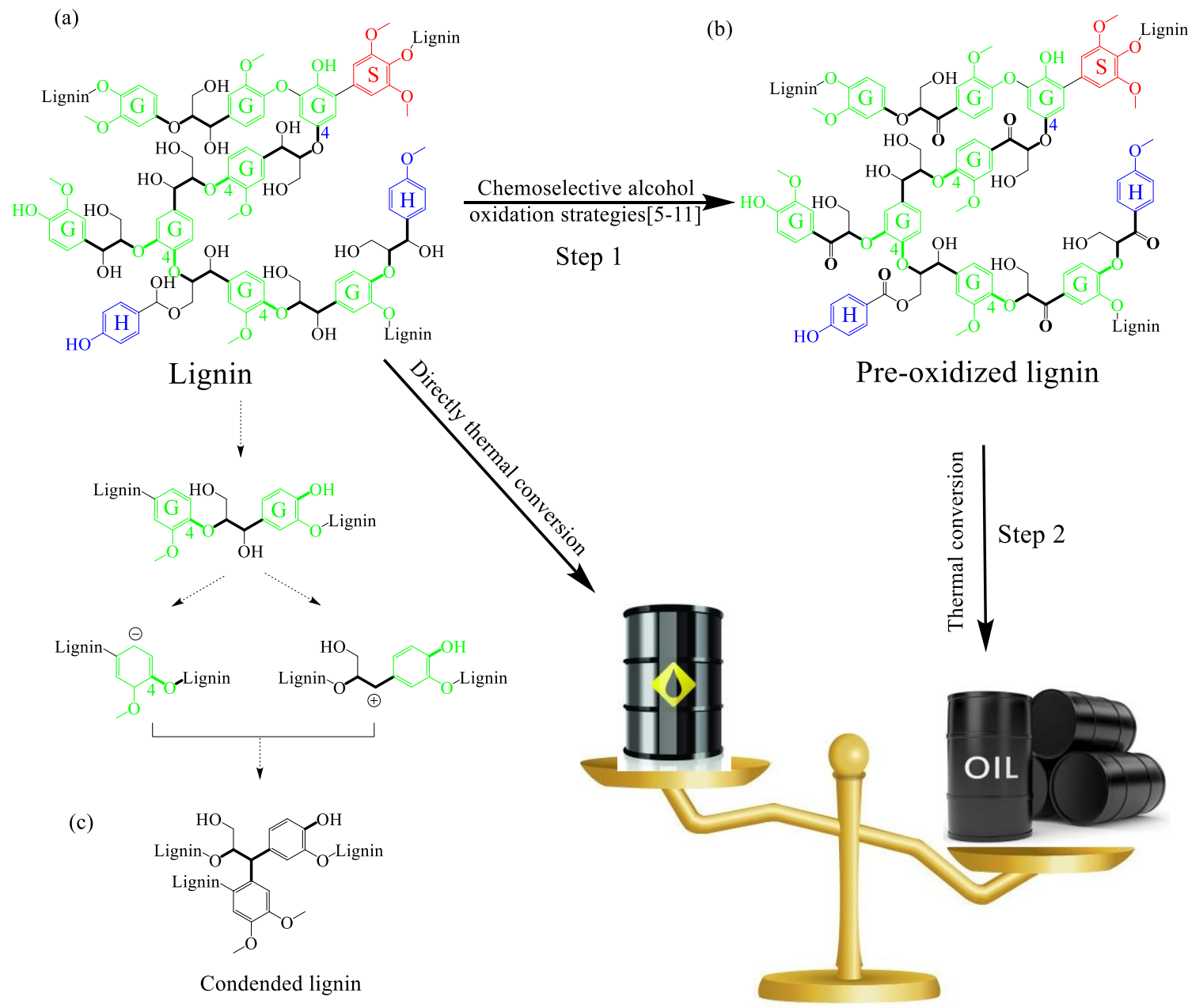

Fig. S1. Typical scheme of lignin oxidation depolymerization 

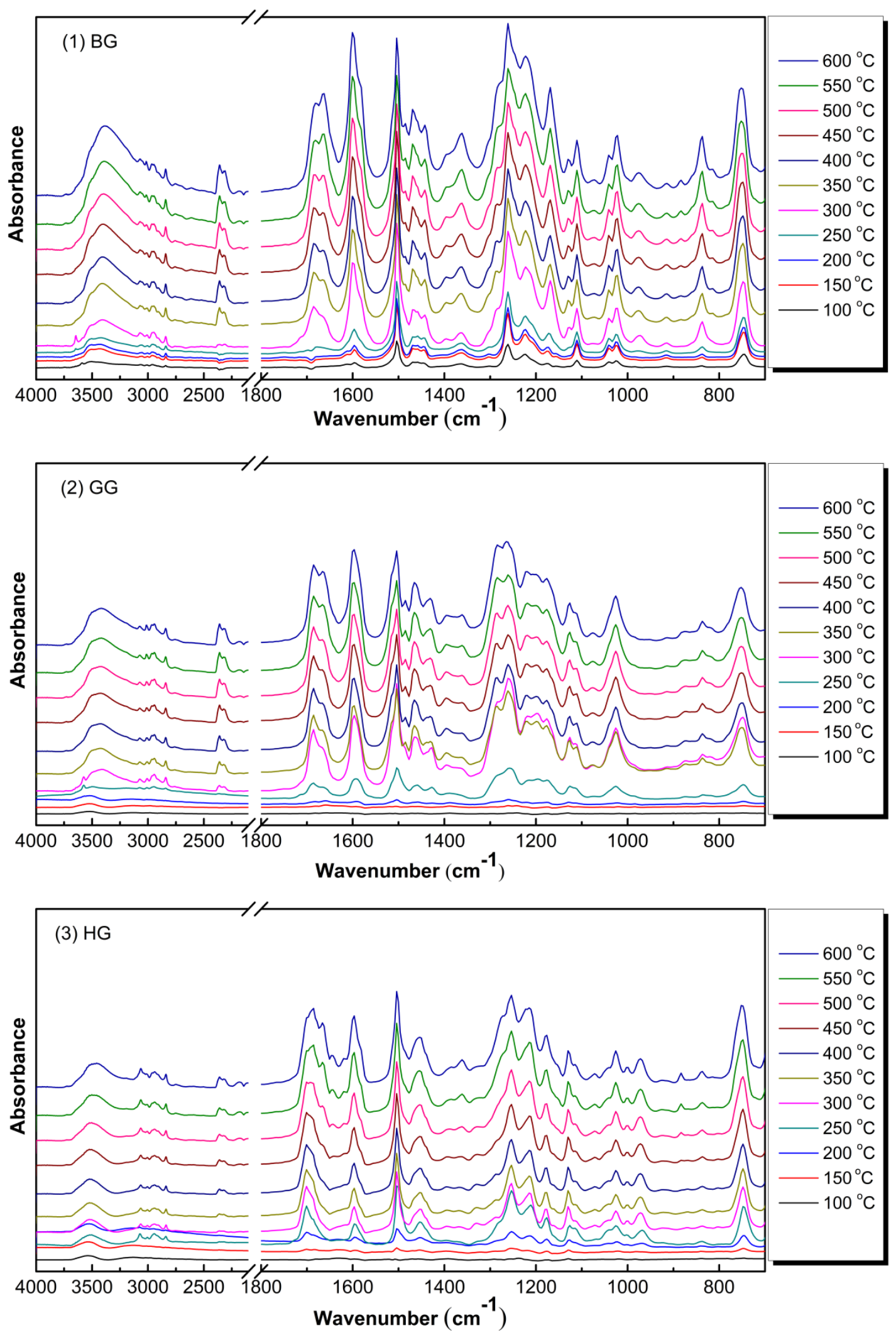

Fig. S2. The real-time monitoring results of volatiles 

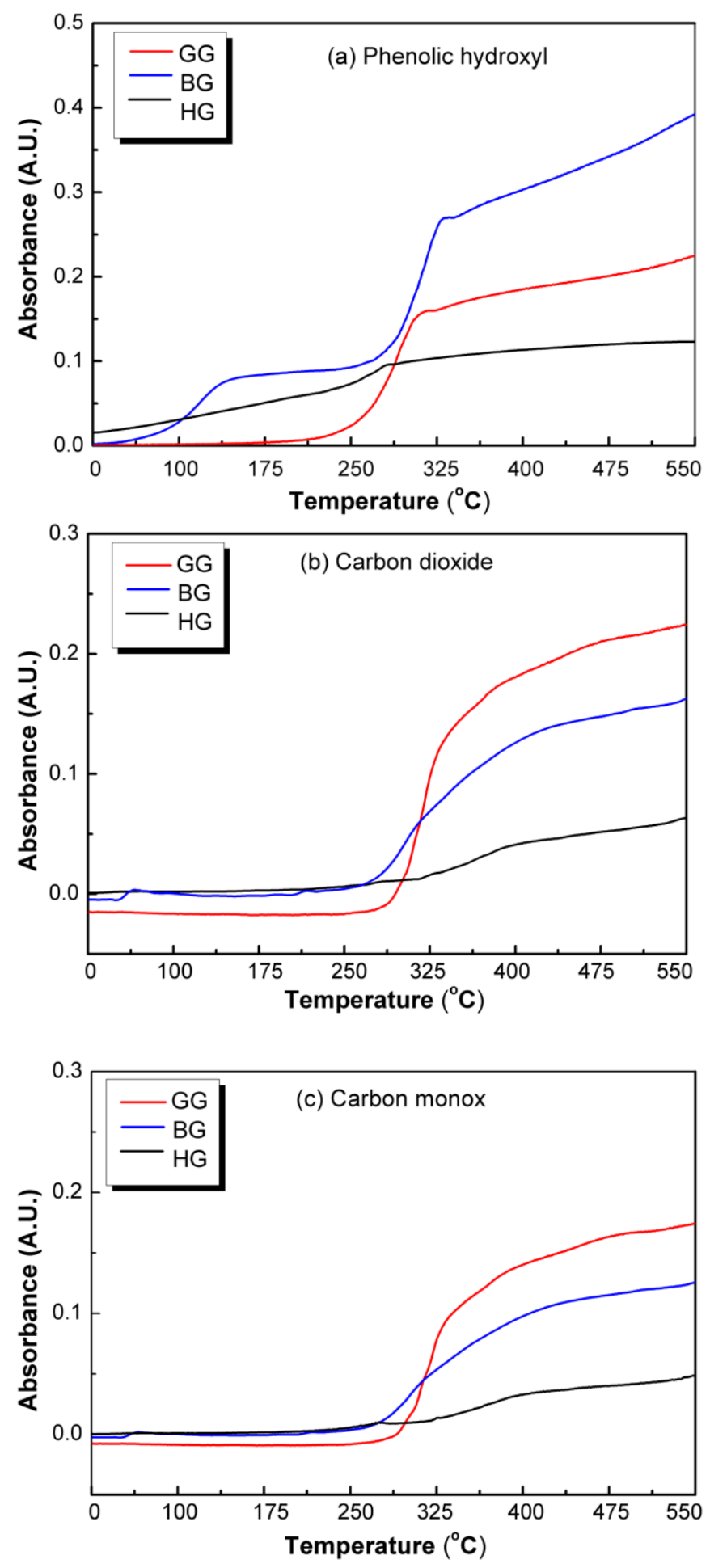

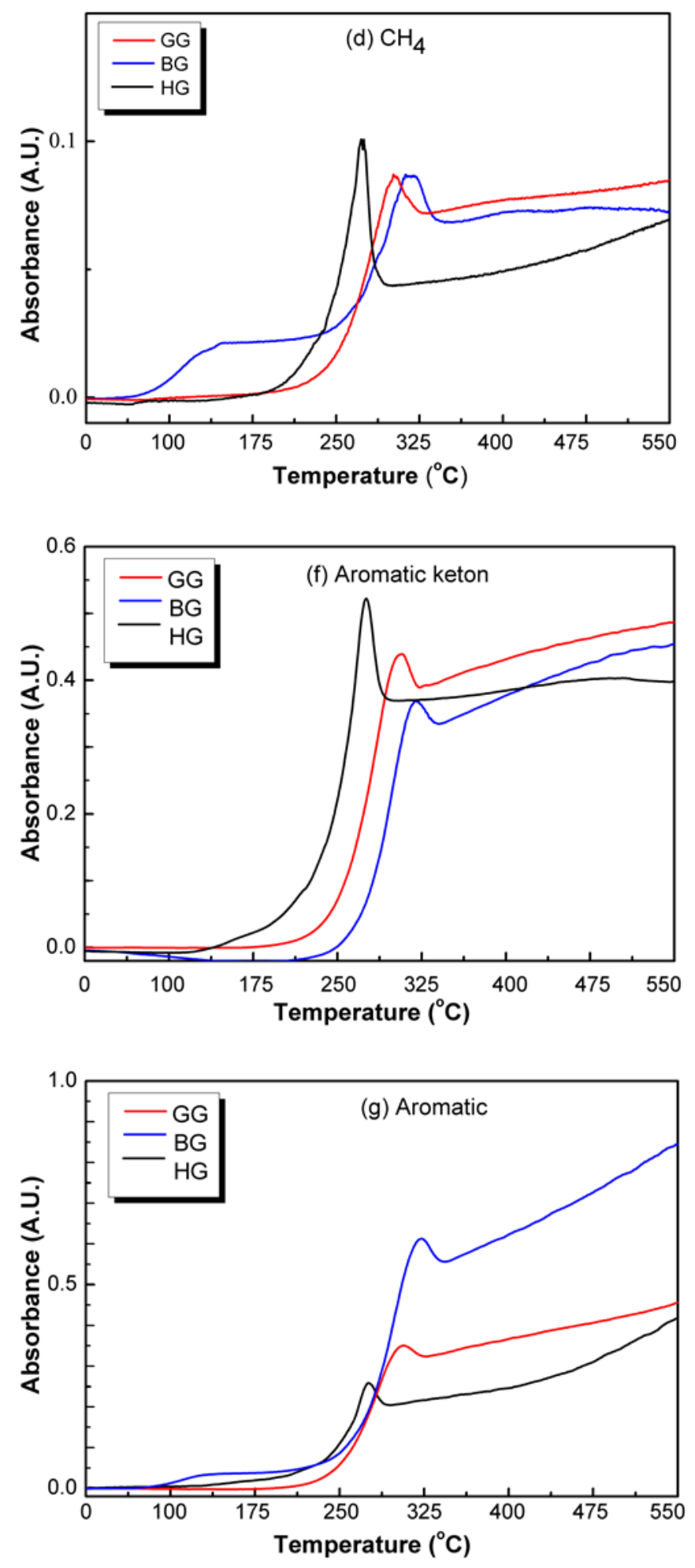

Fig. S3. Temperature-dependent relative intensities of three samples. Time resolution is $1.93 \mathrm{~s}$. 


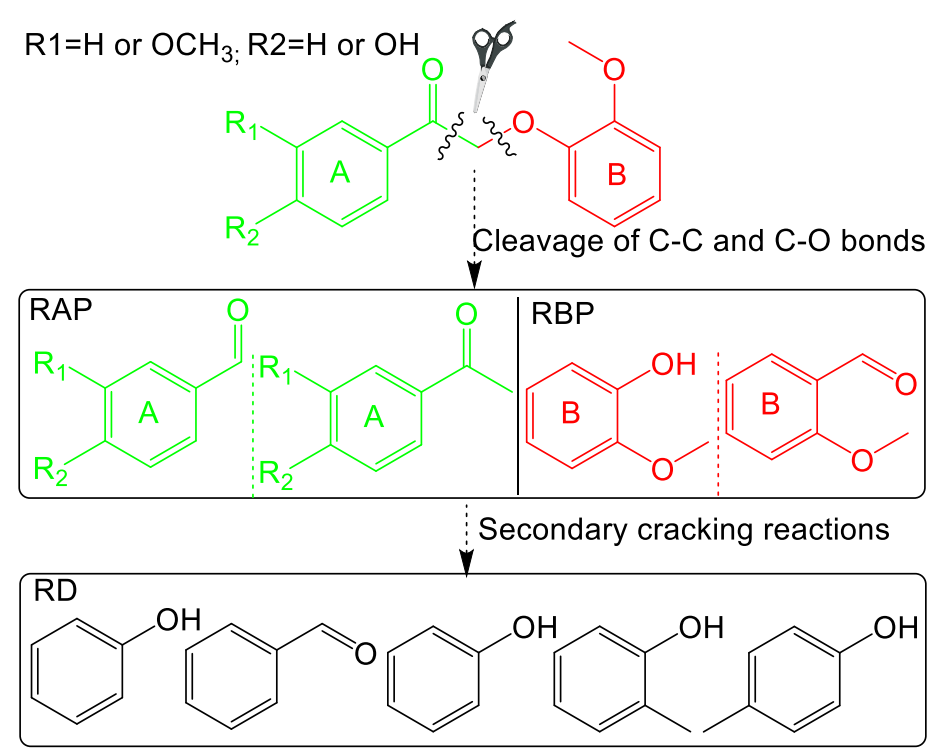

Fig. S4. Primary products (RAP and RBP) and the secondary products (RD).

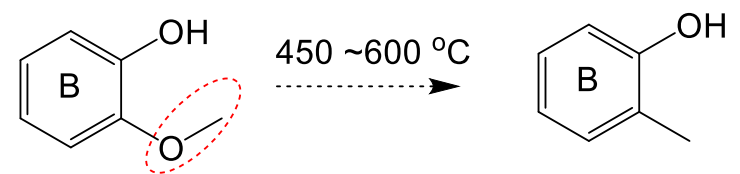

Rearrangement of aryl- $\mathrm{OCH}_{3}$ into aryl- $\mathrm{CH}_{3}$ structure

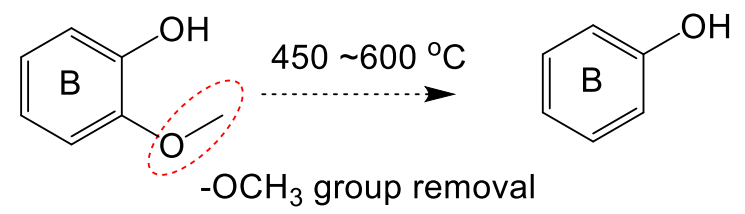

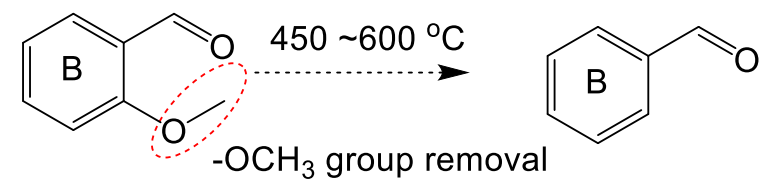

Fig. S5. A schematic diagram of the proposed mechanism of guaiacol and 2-methoxybenzaldehyde 